\title{
To explore the mystery of the idiosyncratic volatility of the A- share market
}

\author{
Ran Zhuoling ${ }^{1, a,}$ Huang Xuehao ${ }^{2, b}$, Xie Mingjia ${ }^{3, c}$ \\ ${ }^{1}$ College of Management, Sichuan Agricultural University, Chengdu, China \\ ${ }^{2}$ College of Economics, Sichuan Agricultural University, Chengdu, China \\ ${ }^{3}$ School of Finance, Southwestern University of Finance and Economics, Chengdu, China
}

\begin{abstract}
Return and risk are inevitable topics in financial research. This paper explores the relationship between IVOL (idiosyncratic volatility) and cross-sectional return (risk premium and excess return) of the Chinese A-share market. With the monthly data of 237 months from January 2001 to September 2019 of Ashare of Shanghai and Shenzhen stock exchange, IVOL of each stock by the regressions is conducted through rolling window based on the four factors model of Carhart. Whether there is a significant positive or negative relationship between the IVOL and the cross-sectional return of the stock by combination analysis and crosssection regression are tested in the paper. The research shows that, after excluding the influence of financial crisis and stock disaster, from January 2001 to September 2019, there is a significant positive relationship between the special volatility and cross-sectional return in Chinese A-share market under normal market conditions, and there is no so-called "mystery of the special volatility".
\end{abstract}

\section{Introduction}

Returns and risks have always been the core issue of financial research. In the development of financial research, the Capital Assets Pricing Model is one of the most classic pricing theory, but many assumptions in this model are too idealistic, without consideration of market frictions such as information asymmetry and the non-systematic risks. Therefore, based on the analysis of incomplete symmetric information, Merton found that the idiosyncratic risk of the company would be reflected in the stock price, and proposed that on the premise of market friction and insufficient investment diversification, the idiosyncratic volatility of the stock was positively correlated with the expected return rate [1].

However, Ang et al. took the American stock market as the research object and found that the idiosyncratic volatility of the American stock market was negatively correlated with its return rate through empirical analysis. This phenomenon, which is contrary to the traditional theoretical model, is called "the mystery of special volatility" [2]. Since then, the test and analysis of the " mystery of the special volatility " have become one of the hot issues in the field of capital asset pricing.

Based on this background, Shanghai and Shenzhen Ashare market are taken as the research object and to verify whether there is the phenomenon of "mystery of special volatility" in the Chinese A-share market through empirical analysis in this paper. The research significance of this paper is as follows:

1. Unlike a large number of literatures that directly conducted regression analysis on the data and did not consider the impact of major events, this paper considers the impact of the global financial crisis in 2008 and the stock market crash in 2015, and takes these two events as nodes to divide the monthly stock data into three samples, which are corresponding with three stages for regression analysis. This paper studies the positive and negative relationship between the idiosyncratic volatility and the expected rate of return in China's a-share market in the past 20 years, and discusses the relationship between the excess yield and the idiosyncratic volatility after considering and eliminating the influence of major events.

2. Based on Carhart four-factor model, rolling window regression is performed in this paper, and portfolio analysis and cross section analysis are combined to verify the results, so as to make the results of empirical analysis more robust.

3. The study of idiosyncratic volatility can promote the steady development of the stock market, risk control, and improve the efficiency of resource allocation in the capital market.

\section{Literature Review}

The traditional capital asset pricing theory assumes that the investors hold sufficiently diversified portfolios, thus suggesting that the idiosyncratic volatility is independent of the expected rate of return. However, Ang et al. found that stocks with high characteristic volatility have lower expected returns through the research on the American stock market, which is known as the " mystery of the special volatility " [2].

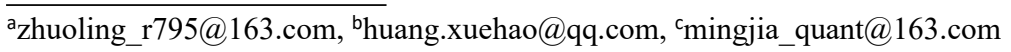


At present, two methods are mainly used to estimate idiosyncratic volatility in the literature: first, the realized idiosyncratic volatility with a lag of one period is directly taken as the expected value. For example, Wang Chunfeng et al. conducted Fama-French three-factor regression on stock data, and then the standard deviation of the residual sequence obtained by the regression is taken as the estimator of stock idiosyncratic volatility; Xiong Xiong et al. made rolling regression based on Fama French fivefactor model, and then took the standard deviation of the residual sequence as the estimate of stock characteristic volatility [3][4]. Second, idiosyncratic volatility is estimated based on time series analysis. For example, Fu uses GARCH and EGARCH models to estimate the expected idiosyncratic volatility [5].

Due to the influence of sample data frequency, sample interval, idiosyncratic volatility estimation method, and proxy variable of expected return, scholars have obtained two different research conclusions: positive relationship and negative relationship.

1. Idiosyncratic volatility is positively correlated with the expected rate of return, that is, there is no "mystery of the special volatility": Fu, Chua et al., Shi Yongdong et al., Wang et al., Luo Dengyue et al. and Xiong Wei et al. found that IVOL is positively correlated with the expected rate of return by different methods [5][6][7][8][9][10].

2. There is a negative relationship between Idiosyncratic volatility and expected rate of return, that is, there is a "mystery of the special volatility": Ang et al. conducted three-factor model regression on the monthly data of the US stock market, and concluded that the stocks with higher idiosyncratic volatility in the US stock market have a lower expected return; Zuo Haomao et al. estimated the idiosyncratic volatility based on GARCH, EGARCH, and ARMA models respectively, and concluded that there was a significant negative relationship between the idiosyncratic volatility and the cross-section return rate in Chinese stock market by using the method of cross-section regression analysis[2][11].

\section{Model And Test}

\subsection{Idiosyncratic Volatility Estimation Model}

It can be seen from the existing literature that model selection has a great influence on the results of idiosyncratic volatility extraction. Currently, most scholars use the standard deviation of the residuals obtained by the Fama-French three-factor model to measure the idiosyncratic volatility, and some scholars extract the idiosyncratic volatility based on the EGARCH model in time series analysis. In this paper, the Carhart four-factor model is used to regress the selected samples, obtaining the results of regression residual, by the standard deviation of residual as the proxy variable of idiosyncratic volatility, then through the analysis of the rolling window analysis method to obtain the time series of the idiosyncratic volatility, and can obtain more information on the time dimension, which makes the results more reliable. The rhart four-factor model used in this paper and the specific equation (1) and equation (2) to estimate the characteristic volatility are as follows:

$$
\begin{gathered}
\begin{array}{r}
r_{i, t}=\alpha_{i}+\gamma_{i, t}^{m k t} M K T_{t}+\gamma_{i, t}^{s m b} S M B_{t}+\gamma_{i, t}^{h m l} H M L_{t} \\
\quad+\gamma_{i, t}^{u m d} U M D_{t}+\epsilon_{i, t},
\end{array} \\
t \in[T-24, T-1] \quad(1) \\
I V O L_{i, t}=\sqrt{\sum_{m=1}^{N} \hat{\epsilon}_{i, m}^{2} /(N-4)}
\end{gathered}
$$

Where, $r_{i, t}$ is the risk premium of stock $i$ in month $t$; $M K T_{t}, S M B_{t}, H M L_{t}$ and $U M D_{t}$ are market risk premium factor, market value factor, book-to-market ratio factor and momentum factor in month $t$, respectively; $T$ is the month of the end of the window; $I V O L_{i, t}$ is the characteristic volatility of stock $i$ in $t$ months; $N$ is the sample observation quantity.

\subsection{Inspection Methods}

\subsubsection{Portfolio Methods}

The portfolio analysis method refers to the construction of different portfolios according to the value of an indicator and examine whether the difference in returns between portfolios is significantly different from zero. Specifically, in this paper, each stock will be divided into five groups according to the average value of idiosyncratic volatility obtained by rolling window regression to compare the returns between these five groups. If there is a significant difference, it means that the special volatility factor may have a certain impact on stock returns; on the contrary, if there is no significant difference between the five groups, it means that the special volatility factor has no impact on stock returns.

\subsubsection{Cross Section Regression Analysis}

After the result of the significant difference is obtained by the method of combination analysis, it can not be directly determined whether the significant difference is caused by the characteristic volatility. Therefore, cross-section regression analysis is also needed to judge the impact of other factors on the rate of return. The cross-sectional regression analysis adds factor coefficient and idiosyncratic volatility into the regression model as explanatory variables so that it can be determined by testing whether the significant difference in the return rate between different portfolios is caused by idiosyncratic volatility.

The method can be divided into two steps:

The first step: in the month $t$, according to Carhart four-factor model to estimate the factor coefficient of stock $i$ in $t$ month, namely $\hat{\beta}_{i}^{m k t}, \hat{\beta}_{i}^{s m b}, \hat{\beta}_{i}^{h m l}, \hat{\beta}_{i}^{u m d}$, the regression equation is the equation (1). Through the method of Rolling window regression, the time series of factor coefficient can be estimated for each stock $i$, and then the average value of each factor coefficient sequence can be taken, then obtain the average value of the factor coefficient of a single stock. Here, the average value calculated by this method is used as the proxy variable of the factor of a single stock. The factor coefficient of a single stock is: $\bar{\beta}_{i}^{m k t}, \bar{\beta}_{i}^{s m b}, \bar{\beta}_{i}^{h m l}, \bar{\beta}_{i}^{u m d}$. 
The second step: the factor coefficients estimated in the first step $\bar{\beta}_{i}^{m k t}, \bar{\beta}_{i}^{s m b}, \bar{\beta}_{i}^{h m l}, \bar{\beta}_{i}^{\text {umd }}$ are substituted into the equation(3). The specific form is as follows:

$$
\bar{R}_{I, i}=\phi_{0, p}+\phi_{1, p} \overline{I V O L_{i}}+\sum_{k=2}^{K} \phi_{k, p} X_{k, i}+\mu_{i}
$$

Where $\bar{R}_{I, i}$ represents the average return of the stock $i$ ( $\mathrm{I}=0$ is the average premium risk, $\mathrm{I}=1$ is the average excess return rate); $\phi_{\tau, p}$ represents the sensitivity coefficient of the $\tau$ factor in the $p$ combination, which represents the influence of the $\tau$ factor on the stock premium, $\overline{I V O L}_{i}$ is the average value of the volatility of the $i$ stock through rolling window regression. $X_{k, i}$ represents other control variables that affect stock crosssectional returns, such as size and turnover rate.

\section{Data Source And Sample Selection}

This paper takes the A-share stocks of Shanghai and Shenzhen stock markets from January 2001 to September 2019 as the research object, with the monthly data of 237 trading months in total. Taking the monthly yield data of individual stocks as the proxy variable of individual stock yield, the four factors selected in the Carhart four-factor model are market risk premium factor, market value factor, book-to-market ratio factor, and momentum factor.

The financial crisis in 2008 and the stock market crash in 2015 seriously distorted the normal developmental trajectory of the market, resulting in an extremely unbalanced tendency of market investment and an inefficient allocation of capital resources. Therefore, to minimize the impact of the two extreme events, this paper divides the sample into three sub-samples. The sample range of the first sample is 72 months from January 2001 to December 2006, which is the sample before the outbreak of the financial crisis in 2008 and is recorded as sample 1; The sample range of the second sample is from January 2009 to January 2015, a total of 72 months. It is a sample from 2008 after the financial crisis to 2015 before the stock disaster, and is recorded as sample 2; The sample interval of the third sample is 45 months from January 2016 to September 2019 and is recorded as sample 3.

In addition, to test the stability of the relationship between idiosyncratic volatility and stock cross-section in the Chinese A-share market, the following control variables are introduced in this paper:

1.Size: Take the natural logarithm of individual stock's current market value as the measurement of size.

2.Turnover: Take the ratio of the turnover amount of each month's individual shares to the current market value of each month's individual shares as a measure of turnover rate.

3.Liquidity: The liquidity of individual stocks in CSMAR database is selected as the measurement index of the liquidity of individual stocks in this paper. The specific calculation method is as follows:

$$
L_{t}^{i}=\frac{1}{N_{i, t}} \sum_{d=1}^{N_{i, t}} \frac{\left|R_{i, t, d}\right|}{V_{i, t}} \text { (4) }
$$

Where $\bar{R}_{I, i}$ and $V_{i, t}$ are respectively the return and trading volume (in millions) of stock $i$ on the $d$ trading day of the month, $N_{i, t}$ refers to the number of days in which stock $i$ is valid for trading in month $t$.

Finally, in addition to the risk-free interest rate from the RESSET financial research database, the sample data used in this paper include data related to stock returns and Carhart four factors, which are all from the CSMAR database.

\section{Empirical Results And Test Analysis}

\subsection{Descriptive Statistical Analysis}

First, descriptive statistical analysis was conducted on each variable, and the results are shown in Table 1. It can be seen that the mean values of the idiosyncratic volatility (IVOL) of the three samples are $6.4 \%, 7.9 \%$, and $7.6 \%$, respectively. It can be seen that the idiosyncratic volatility of sample 1 is relatively small compared with that of sample 2 and sample 3 . Also, the mean value of risk premium (Rirf) is $-0.2 \%, 1.8 \%$, and $-0.3 \%$ respectively, indicating that in the three sample ranges studied, the average yield of sample 2 is the highest, that is, from January 2009 to January 2015.

\begin{tabular}{|c|c|c|c|c|c|c|c|c|c|c|c|c|c|c|c|}
\hline & \multicolumn{5}{|c|}{ Sample 1} & \multicolumn{5}{|c|}{ Sample 2} & \multicolumn{5}{|c|}{ Sample 3} \\
\hline & Min & Median & Max & Mean & Std & Min & Median & Max & Mean & Std & Min & Median & Max & Mean & Std \\
\hline IVOL & 0.03 & 0.06 & 0.15 & 0.06 & 0.02 & 0.02 & 0.08 & 0.29 & 0.08 & 0.02 & 0.02 & 0.07 & 0.28 & 0.08 & 0.03 \\
\hline Rirf & -0.78 & -0.01 & 3.90 & 0.00 & 0.12 & -0.65 & 0.01 & 22.05 & 0.02 & 0.16 & -0.85 & -0.02 & 5.73 & 0.00 & 0.13 \\
\hline MKT & -0.14 & 0.00 & 0.22 & 0.00 & 0.07 & -0.22 & 0.01 & 0.19 & 0.01 & 0.07 & -0.08 & 0.00 & 0.14 & 0.00 & 0.05 \\
\hline SMB & -0.13 & -0.01 & 0.12 & -0.01 & 0.04 & -0.23 & 0.01 & 0.11 & 0.01 & 0.05 & -0.08 & -0.01 & 0.07 & -0.01 & 0.04 \\
\hline HML & -0.03 & 0.01 & 0.07 & 0.01 & 0.02 & -0.07 & 0.00 & 0.16 & 0.00 & 0.03 & -0.09 & 0.00 & 0.08 & 0.00 & 0.03 \\
\hline UMD & -0.11 & 0.01 & 0.12 & 0.01 & 0.05 & -0.19 & 0.01 & 0.12 & 0.00 & 0.05 & -0.15 & 0.02 & 0.08 & 0.01 & 0.05 \\
\hline Size & 10.13 & 13.46 & 18.16 & 13.47 & 0.84 & 11.87 & 14.85 & 21.38 & 14.98 & 1.11 & 11.47 & 15.43 & 21.43 & 15.54 & 1.11 \\
\hline Turnover & 0.00 & 0.01 & 0.45 & 0.01 & 0.02 & 0.00 & 0.02 & 0.45 & 0.03 & 0.03 & 0.00 & 0.01 & 0.52 & 0.02 & 0.04 \\
\hline Liquidity & 0.00 & 0.00 & 18.23 & 0.01 & 0.07 & 0.00 & 0.00 & 11.59 & 0.00 & 0.04 & 0.00 & 0.00 & 113.59 & 0.00 & 0.43 \\
\hline
\end{tabular}

Table1. DESCRIPTIVE STATISTICS

5.2 The relationship between idiosyncratic volatility and cross-sectional stock returns
After the descriptive statistical analysis of the experimental data, this paper will firstly analyze the relationship between idiosyncratic volatility and stock 
returns by using the portfolio analysis method. Specifically, first of all, all stocks are divided into five portfolios based on idiosyncratic volatility, and then calculate the average risk premium $(R M R F)$ and average excess return (Alpha) for each combination, then Student$\mathrm{t}$ statistics is used to test whether the difference between the average risk premium and average excess return of the highest and lowest idiosyncratic volatility in each portfolio is significantly not equal to zero. If the difference between the two returns is significantly greater than zero,

Table2. PORTFOLIO CHARACTERISTIC VOLATILITY AND ITS RATE OF RETURN

\begin{tabular}{|c|c|c|c|c|c|c|c|c|c|}
\hline \multicolumn{4}{|c|}{ Sample 1} & \multicolumn{3}{|c|}{ Sample 2} & \multicolumn{3}{|c|}{ Sample 3} \\
\hline & IVOL (\%) & RMRF (\%) & $\begin{array}{c}\text { CH4-Alpha } \\
(\%)\end{array}$ & IVOL (\%) & RMRF (\%) & $\begin{array}{c}\text { CH4-Alpha } \\
(\%)\end{array}$ & IVOL (\%) & RMRF (\%) & $\begin{array}{c}\text { CH4-Alpha } \\
(\%)\end{array}$ \\
\hline Low IVOL & 4.2345 & -0.6078 & -0.2587 & 5.1153 & 0.9491 & -0.6975 & 4.1491 & -0.7013 & -0.6887 \\
\hline 2 & 5.2840 & -0.2675 & 0.0354 & 6.6288 & 1.2932 & -0.4821 & 5.8207 & -0.5992 & -0.3865 \\
\hline 3 & 6.0751 & -0.2018 & 0.1698 & 7.5614 & 1.6597 & -0.1583 & 7.1322 & -0.2944 & -0.1752 \\
\hline 4 & 7.1065 & -0.1553 & 0.2976 & 8.6512 & 1.9472 & 0.1021 & 8.7046 & -0.2226 & -0.0861 \\
\hline High IVOL & 9.1419 & 0.4579 & 0.6661 & 11.4272 & 2.8456 & 0.7638 & 12.2314 & 0.2668 & 0.3427 \\
\hline $\begin{array}{l}\text { High- } \\
\text { Low }\end{array}$ & & $\begin{array}{l}1.0640^{* * *} \\
(8.27)\end{array}$ & $\begin{array}{l}0.9224^{* * *} \\
(8.87)\end{array}$ & & $\begin{array}{l}1.8965^{* * *} \\
(15.61)\end{array}$ & $\begin{array}{l}1.4613^{* * *} \\
(16.19)\end{array}$ & & $\begin{array}{l}0.9434^{* * *} \\
(8.32)\end{array}$ & $\begin{array}{c}1.0314^{* * *} \\
(9.95)\end{array}$ \\
\hline
\end{tabular}

Sample 1

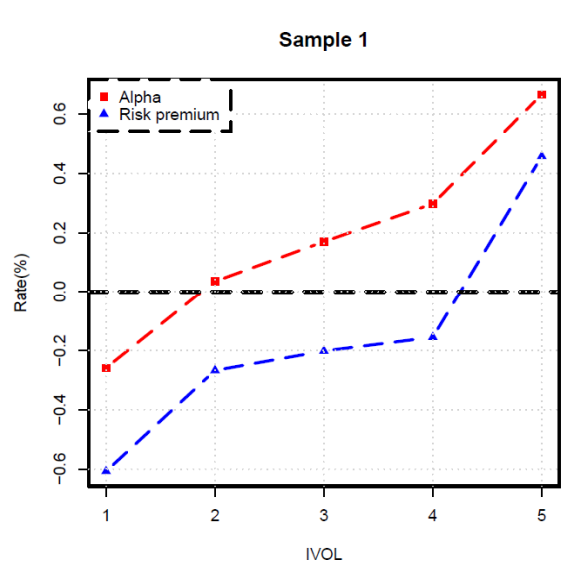

it means that the relationship between the special volatility and the cross-sectional return of the stock is significantly positive. On the contrary, if the difference between the two returns is significantly less than 0 , it means that the relationship between the special volatility and the crosssectional return of the stock is significantly negative. Otherwise, there is no significant positive and negative relationship between the special volatility and the crosssectional return of the stock.
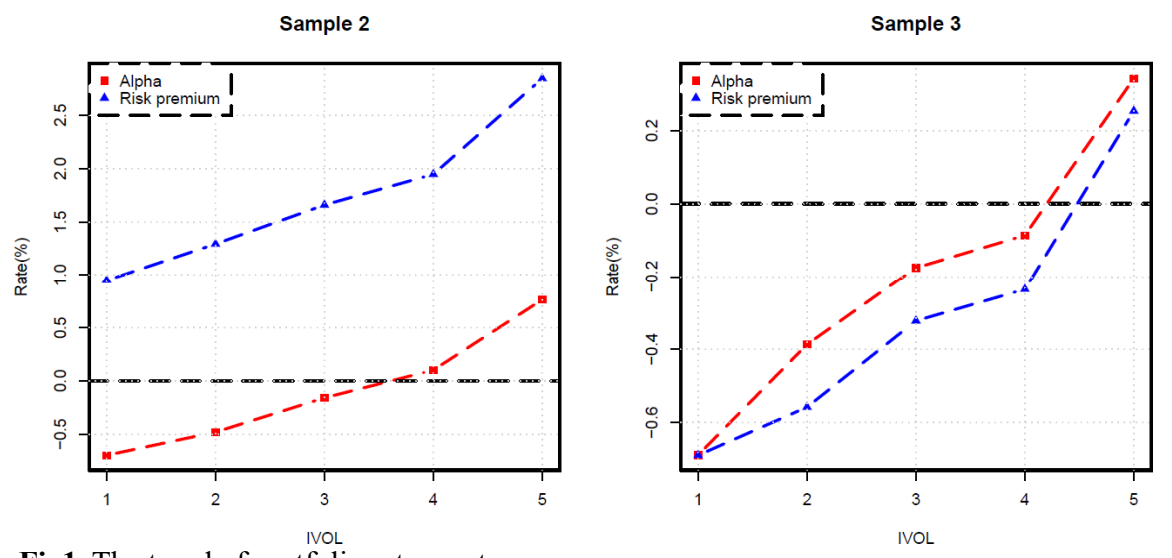

Table 2 shows the results of portfolio analysis based on the Carhart four-factor model regression, including the average idiosyncratic volatility, average risk premium, and average excess yield of all IVOL portfolios under each sample. It can be seen that the average values of High IVOL of sample 1, sample 2, and sample 3 are $9.1419 \%$, $11.4272 \%$, and $12.2314 \%$ respectively, and the average values of Low IVOL are $4.2345 \%, 5.1153 \%$, and $4.1491 \%$ respectively. Besides, all the difference of the average risk premium between the highest IVOL portfolio and the lowest IVOL portfolio of the three samples are greater than zero, with values of $1.0309 \%, 1.8912 \%$, and $0.9681 \%$, and all Student $-t$ statistics are significant at the level of $1 \%$. The difference of their average excess returns is also greater than zero, with values of $1.0640 \%, 1.8965 \%$, and $0.9434 \%$, and their Student $-t$ statistics were also significant at the level of $1 \%$. As shown in figure 1 , the horizontal axis represents the IVOL portfolio (average idiosyncratic volatility is ranked from low to high). It can be seen that the average risk premium and average excess return of the portfolio increase with the increase of the average idiosyncratic volatility of the portfolio.

The above results show that, based on the combined analysis method of Carhart four-factor regression model,

the results of samples before the financial crisis (sample1), before the stock market crash after the financial crisis(sample 2) and after the stock market crash (sample 3) all show that the relationship between idiosyncratic volatility and cross-sectional returns of stocks is positive. The above results are different from the significant negative relationship (the existence of idiosyncratic volatility) shown in many works of literature in China, that is, the positive and negative relationship between the two is controversial. But it is not enough to prove that the relationship between the idiosyncratic volatility and the cross-sectional return of stocks is positive just base on the portfolio analysis method. Therefore, it is necessary to test the stability of the positive relationship between idiosyncratic volatility and stock cross-sectional returns.

\subsection{Robustness Test}

To test the stability of the positive relationship between idiosyncratic volatility and cross-sectional returns, the Fama-Macbeth cross-sectional regression method will be used in this paper to simultaneously control the influence of multiple variables, so as to analyze the relationship between idiosyncratic volatility and stock cross-sectional 
returns more fully. The Fama-Macbeth cross-section regression equation is as follows:

$$
\bar{R}_{I, i}=\phi_{0, p}+\phi_{1, p} \overline{I V O L_{i}}+\sum_{k=2}^{K} \phi_{k, p} X_{k, i}+\mu_{i}
$$

Where $\bar{R}_{I, i}$ represents the average return of the stock $i$ is the average risk premium, ( $\mathrm{I}=0$ is the average premium risk, $\mathrm{I}=1$ is the average excess return rate); $\phi_{\tau, p}$ represents the sensitivity coefficient of the $\tau$ factor in the $p$ combination, which represents the influence of the $\tau$ factor on the stock premium, $\overline{I V O L}_{i}$ is the average value of the volatility of the stock $i$ through rolling window regression. $X_{k, i}$ represents other control variables that affect stock cross-sectional returns, such as size and turnover rate.

Table3. CROSS SECTION REGRESSION RESULTS-SAMPLE 2

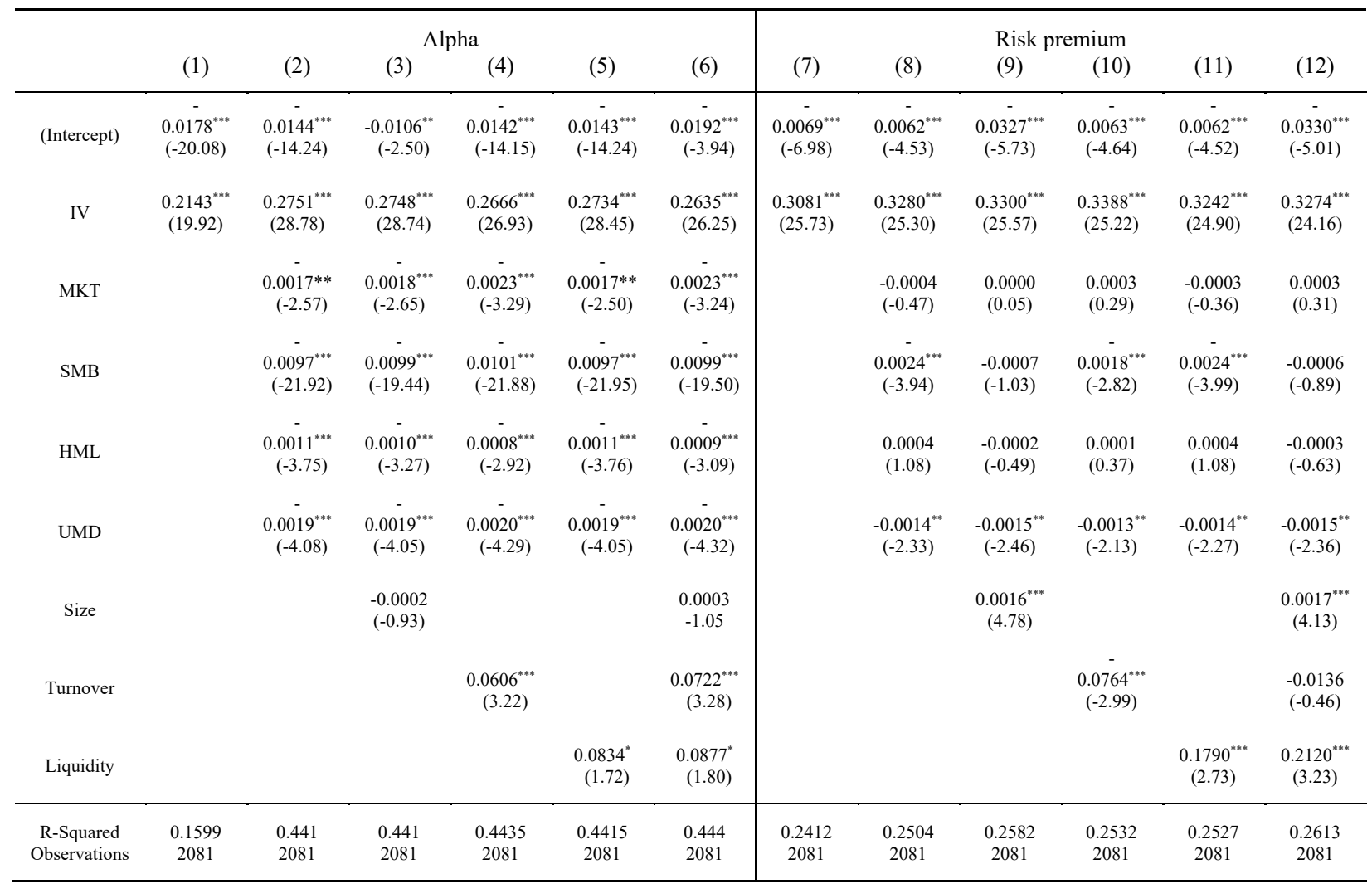

Due to the limited layout, this paper will only take sample 2 as an example to illustrate this phenomenon. It can be seen from Table III that in the model (1) and model (7) which just include the idiosyncratic volatility, the relationship between the idiosyncratic volatility and the stock cross-sectional excess return and risk premium is also significantly positive at the $1 \%$ significant level. From the results of the model (2) and model (8), it can be seen that the $R^{2}$ of the regression model of crosssectional excess return on stocks has increased relative to model (1) and model (7) and the relationship between idiosyncratic volatility and risk premium is positive. Although the change of $R^{2}$ of risk premium is very small, the relationship between idiosyncratic volatility and risk premium is still positive. Although in the following regression, based on the model (2) and model (8), we add the market value, turnover and liquidity variables respectively, which does not make the explanatory power of the regression model significantly enhanced due to the adjustment of factors. Moreover, when the control variables are changed, the regression coefficient of idiosyncratic volatility is not greatly affected and is still significantly positive at the $1 \%$ significant level.

In model (10), the regression coefficient of Turnover is
-0.0764 , which is significantly negative at the significant level of $1 \%$, indicating that stocks with a lower turnover rate will obtain a higher risk premium. The lower the turnover rate, the lower the liquidity of the stock, which makes the liquidity risk higher. In order to compensate for liquidity risk, investors require higher expected returns, which indicates that liquidity premium exists in the Chinese stock market from January 2009 to January 2015. Finally, combined with figure 1, it can be concluded that there is a significant positive relationship between the stock idiosyncratic volatility and the stock cross-sectional return in the Chinese A-share market from January 2009 to January 2015. Similarly, the robust test of sample 1 and sample 3 gives the same conclusion.

To sum up, after excluding the impact of the financial crisis and stock disaster and other major events, from January 2001 to September 2019, even if various control variables are added, the impact of special volatility on expected earnings is still significantly positive at the $1 \%$ significant level. This shows that this positive relationship cannot be explained by other explanatory variables, so there is no so-called "mystery of idiosyncratic volatility" in the Chinese A-share market. 


\section{Conclusion And Revelation}

Since Ang et al. (2006) published the research results on the significant negative relationship between stock idiosyncratic volatility and cross-sectional return, the test and analysis of "the mystery of idiosyncratic volatility" has become one of the hot issues in the field of asset pricing. In the actual trading environment of market friction factors such as information asymmetry, legal constraints, and transaction costs, it is impossible for investors to hold a fully decentralized portfolio. Based on this fact, many scholars have theoretically confirmed that there should be a positive relationship between the idiosyncratic volatility and the cross-sectional return of stocks, but the empirical test results are different. [2].

This paper takes the trading data of the Shanghai and Shenzhen a-share markets from January 2001 to September 2019 as the experimental sample. Considering the impact of the financial crisis in 2008 and the stock market crash in 2015, the sample is divided into three subsamples, and the idiosyncratic volatility of A-stock is calculated based on the Carhart four-factor regression model. Then, portfolio analysis and cross-sectional regression analysis are used to analyze the relationship between idiosyncratic risk and stock cross-sectional return and the result shows that there is a significant positive relationship between idiosyncratic risk and stock crosssectional return. Even after considering and controlling the factors that influence the expected return, such as the market value of circulation, the turnover rate of momentum effect and liquidity, the positive relationship between the special volatility and the cross-sectional return of stock still holds, and it is stable in different time intervals, which further shows that there is no so-called "mystery of the special volatility" in the Chinese stock market.

\section{References}

1. ROBERT, C, MERTON, "A Simple Model of Capital Market Equilibrium with Incomplete Information", Journal of Finance. vol. 42, no. 3, pp. 483-510, July 1987.

2. Ang A, Hodrick R J , Xing Y , Zhang X, “ High idiosyncratic volatility and low returns: International and further U.S. evidence", Journal of Financial Economics. June 2007.

3. Wang Chunfeng, Yao Shouyu, Fang Zhenming, "Fattailed Distribution of Stock Returns, Idiosyncratic Volatility, and Stock Price Behavior", Systems Engineering. vol. 35, no. 12, pp. 1-14, December 2017.

4. Xiong Xiong, Meng Yongqiang, Li Ran, Shen Dehua, "Idiosyncratic volatility and stock returnsResearch based on Fama-French five-factor model", Journal of Systems Science and Mathematical Sciences. vol. 37, no. 07, pp. 1595-1604, July 2017.

5. Fu F, "Idiosyncratic risk and the cross section of expected stock returns",Cfa Digest. vol. 91, no. 1, pp. 24-37, 2009.
6. CHUA, Choong Tze, GOH, Choo Yong, Jeremy, ZHANG, Zhe (Joe), " Idiosyncratic Volatility Matters for the Cross-Section of Returns - in More Ways Than One! ", China International Conference in Finance. July 2006.

7. Shi Yongdong, Li Fengyu, Yang Yunpeng, "An Empirical Study for Dynamic Relationship between Stock Returns and Idiosyncratic Volatility", Review of Investment Studies. vol. 31, no. 9, pp. 6-19, September 2012.

8. Wang, Mu-Shun, "Idiosyncratic risk and expected returns: a panel data model with random effects", Applied Financial Economics. vol. 23, no. 10, pp. 869-880, March 2013.

9. Luo Dengyue, "Idiosyncratic volatility and crosssectional returns: a test based on the Fama-French stock portfolio", Statistics \& Decision. no. 4, pp. 167169, February 2013.

10. Xiong Wei, Chen Liangnan, "Idiosyncratic Volatility, Stock Return and Investor Sentiment",Journal of Management Science. vol. 28, no. 05, pp. 106-115, September 2015.

11. Zuo Haomiao, Zhen ming, Zhang Yi, "Idiosyncratic volatility and cross-sectional returns: an explanation of the "idiosyncratic volatility puzzle" in Chinese stock markets ",The Journal of World Economy. vol. 34, no. 5, pp. 117-135, May 2011. 